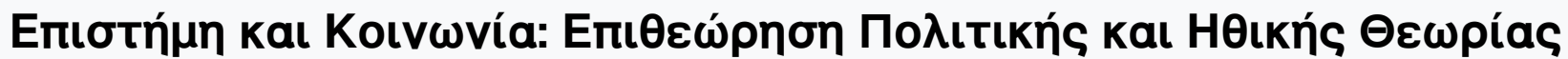

Tóp. 8 (2002)

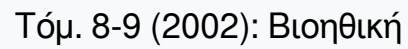

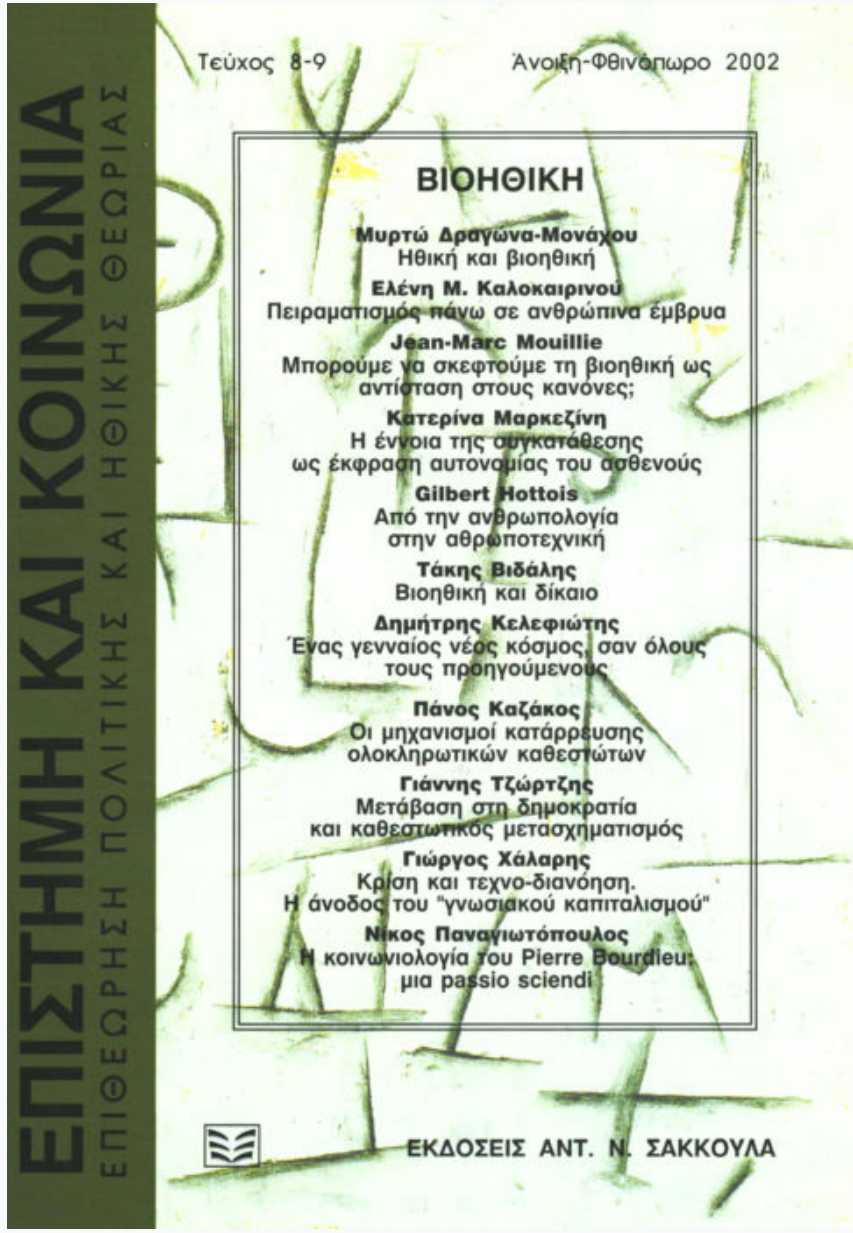

\section{Gilbert Hottois et Jean-Noel Missa, Nouvelle encyclopédie de bioethique: Medecine, Environement, Bioechnologie}

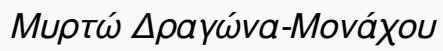

doi: $10.12681 /$ sas.732

Copyright @ 2015, Muptú $\Delta$ payẃva-Mováxou

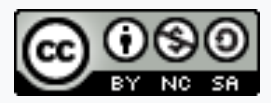

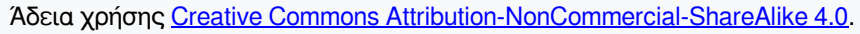

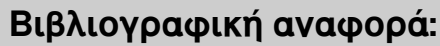

$\Delta$ payẃva-Mováxou M. (2015). Gilbert Hottois et Jean-Noel Missa, Nouvelle encyclopédie de bioethique: Medecine,

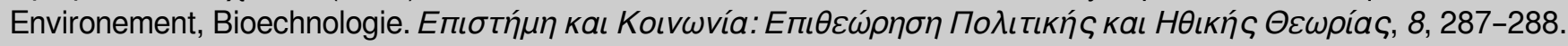
https://doi.org/10.12681/sas.732 


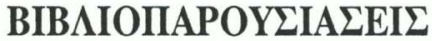

Gilbert Hottois et Jean-Noel Missa, Nouvelle encyclopedie de bioethique: Medecine, Environement, Bioechnologie, Bruxelles, De Boeck Universite, 2001, $922 \sigma \varepsilon \lambda$

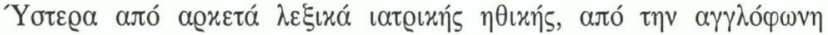

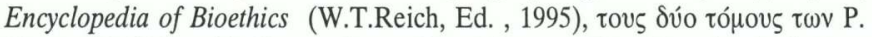
Singer -E. Kuhse (A Companion to Bioethics ra Bioethics: An Anthology

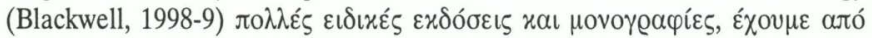

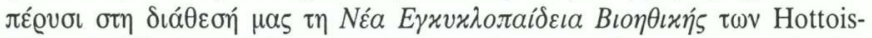

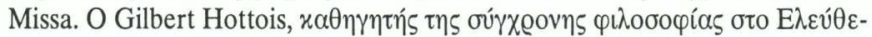

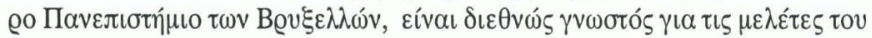

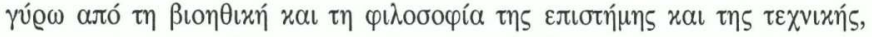

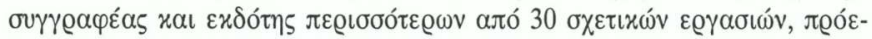

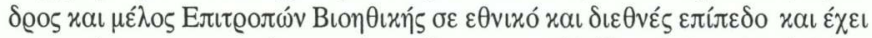

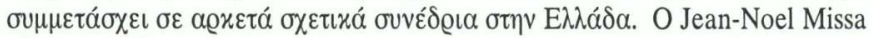

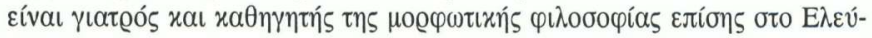

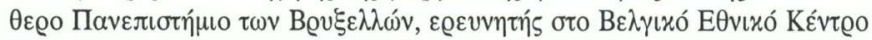

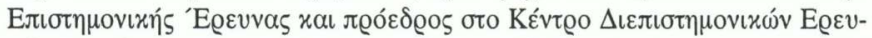

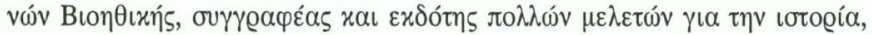

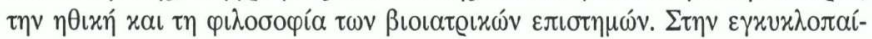

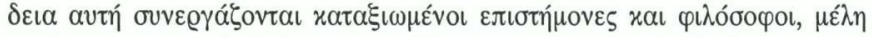

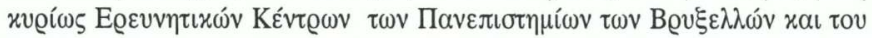

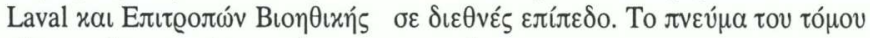

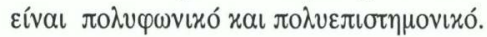

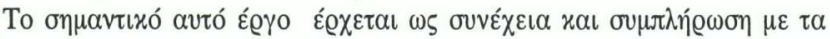

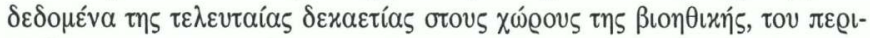

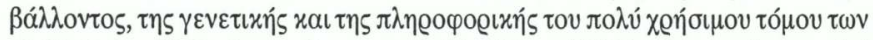
G. Hottois - H. Parizeau, Les mots de bioethique (1993). А

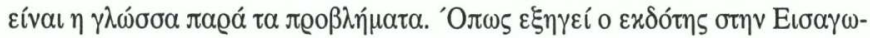




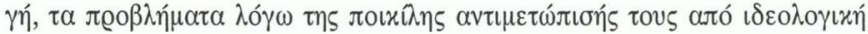

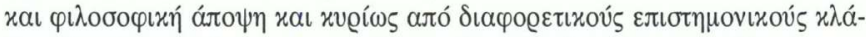

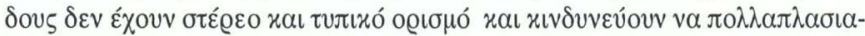

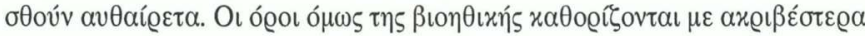

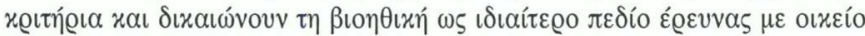

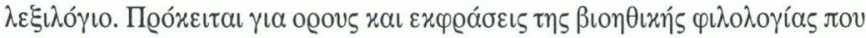

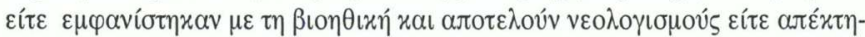

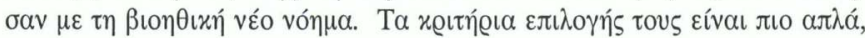
$\alpha$

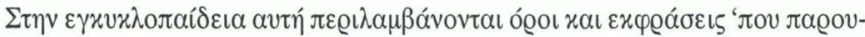

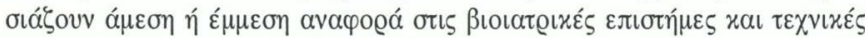

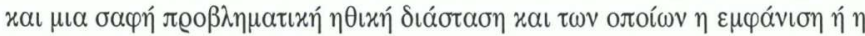

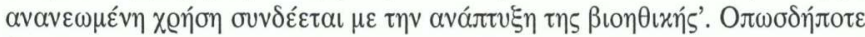

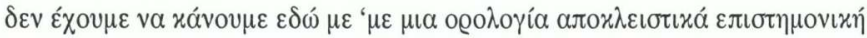

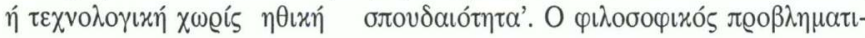

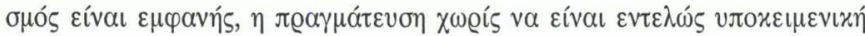

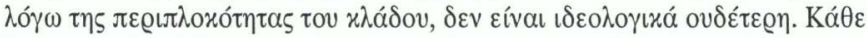

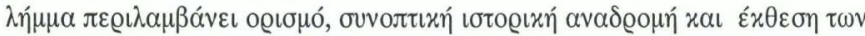

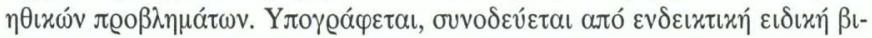

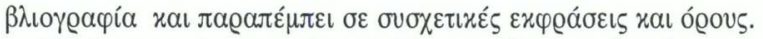

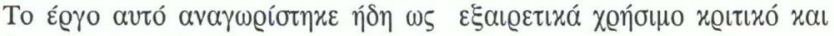

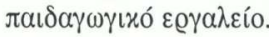

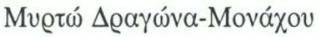

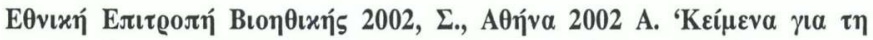

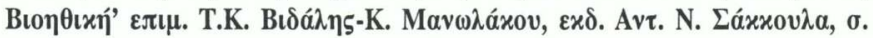
493 ISBN: 960-15-0716-7.

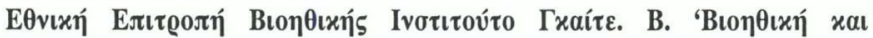

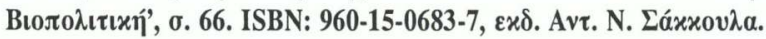

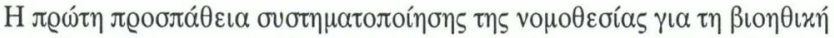

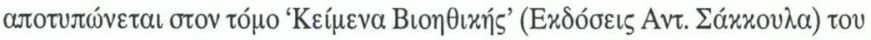

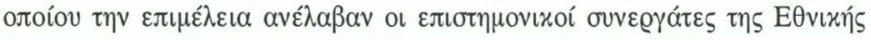

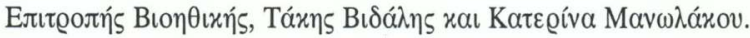

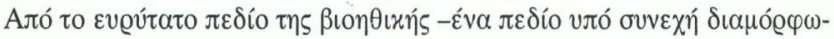

